\title{
SISTEM MONITORING SUHU, ASAP DAN API RUANGAN SERVER INFORMATION AND COMMUNICATION TECHNOLOGY (ICT) UNIVERSITAS BINA INSAN MENGUNAKAN ARDUINO BERBASIS WEBSITE
}

\author{
Taufik Rahman ${ }^{1}$, Andri Anto Tri Susilo ${ }^{2}$, Wiwit Lestari ${ }^{3}$ \\ ${ }^{1,2}$ Program Studi Informatika, Universitas Bina Insan, Lubuklinggau \\ ${ }^{3}$ Program Studi Rekayasa Sistem Komputer, Universitas Bina Insan, Lubuklinggau \\ e-mail: *1taufik_rahman@univbinainsan.ac.id, ${ }^{2}$ andriantotrisusilo@univbinainsan.ac.id, \\ ${ }^{3}$ wiwitlestari@univbinainsa.ac.id
}

\begin{abstract}
Abstrak
Tujuan dari Penelitian ini adalah untuk membuat alat monitoring ukur pada perangkat server dengan menggunakan sensor DHT11 sebagai sensor suhu, MQ-2 sebagai sensor asap dan DFR0011 sebagai sensor api pada objek yang diteliti dan sistem website yang menyimpan hasil sensor secara otomatis kedalam database. Arduino sebagai pemrosesan data dan memanfaatkan website sebagai sarana informasi sehingga data yang disajikan bisa secara terus menerus tanpa harus menggunakan sistem manual. Metode penelitian yang digunakan dalam penelitian ini adalah metode prototype. Alat ukur ini dibuat menggunakan modul Arduino Uno yang diprogram dengan menggunakan bahasa pemrograman $\mathrm{C}$ dan sebagai antarmuka pada personal computer menggunakan bahasa pemrograman PHP MySql. Berdasarkan hasil penelitian dapat disimpulkan bahwa: 1. Sistem Monitoring Suhu, Asap dan Api Ruangan ICT Server memberikan dapat informasi secara berkala mengenai temperatur ruangan. 2. Alat monitoring ruangan ini dapat membantu menampilkan hasil sensor yang disimpan di database dan dapat ditampilkan di website sehingga dapat membantu bagian administrator dalam memonitoring selama 24 jam secara realtime..
\end{abstract}

Kata kunci-Sensor Suhu, Asap dan Api, Monitoring, Website

\[ \begin{array}{c}\text { Abstract } \\ \text { The objective of this study is to make monitoring tool to measure server by using sensor }\end{array} \]
. DHT1 1 as a temperature sensor, MQ-2 as a smoke sensor and DFR0011 as a flame sensor for researching object. Website system will save the sensor results to database automatically. Arduino as a data processing and use website as information facilities. It makes data will update continously without manual system. The study method used is prototype method. The measuring tool is made by using modul Arduino Uno which is programmed by using $C$ programming language and as an interface on personal computer using PHP MySql programming language. Based on the study result, it can be concluded that 1. Monitoring system of temperature, smoke, and fire in ICT server room can give periodic information about room temperature. 2. This room monitoring tool can help to display sensor result which is stored on database. It can be displayed on website so it can help administrator to monitor 24 hours in realtime.

Keywords - Temperature, Smoke Sensor and Flame Sensor, Monitoring, Website 


\section{PENDAHULUAN}

Keahlian dibidang Teknologi Informasi dan Komunikasi (TIK) atau dikenal dengan istilah ICT (Informationand Communication Technology) sangat penting di era perkembangan teknologi saat ini.. Salah satu pemanfaatan perkembangan teknologi pada suatu lembaga pendidikan dapat dilihat pada proses penyimpanan data di server.

Server pada suatu lembaga pendidikan terutama di ICT memiliki fungsi yang sangat penting dalam seluruh proses layanan data, proses pengatur lalu lintas jaringan dan juga instalasi seluruh program aplikasi dan database sehingga sehingga perlu keamanan informasi yang baik. Keamanan informasi pada server juga tidak terlepas dari kondisi fisik ruangannya. Keamanan pada ruang server memegang peranan penting pada proses operasionalnya. Sehingga sebuah ruang server harus memiliki standar keamanan yang tinggi agar dapat melindungi komputer server mulai dari suhu udara, kelembaban dan kebakaran. ICT Universitas Bina Insan merupakan divisi yang bertanggung jawab pada layanan server, teknologi informasi dan sistem informasi yang ada di Universitas Bina Insan. Di ruang server ICT Universitas Bina Insan yang sering memiliki tingkat suhu dan kelembaban tinggi, sehingga mengakibatkan lambatnya kinerja satu dengan yang lain, menyebabkan perangakat overheat yang dapat mengakibatkan kebakaran ruang server. Sehingga suhu merupakan salah satu hal utama yang sangat berpengaruh terhadap kelancaran, kualitas maupun keamanan suatu jaringan dan perangkat dalam ruang server.

Hal ini mengarah kepada pentingnya menjaga stabilitas suhu ruang server ICT sehingga bahaya kebakaran yang berakibat fatal dapat diatasi dengan pemantauan suhu secara berkala. Akan tetapi pengawasan dan pemantauan tidak akan efektif dan efesien jika hanya mengandalkan kemampuan manusia. Tidak akan mungkin bagian administrator ICT selaku penanggung jawab ruangan berada terus menerus diruangan server selama 24 jam hanya untuk melakukan pengawasan suhu ruangan saja karena waktu kerja yang sangat terbatas.

Untuk membantu bagian administrator memantau suhu ruang pada perangkat server, diperlukan alat ukur dengan menggunakan mikrokontroler dan sensor yang dapat mengukur suhu bahkan mendeteksi asap dan api pada perangkat server tersebut. Sehingga pembuatan alat ukur otomatis sangat cocok untuk diterapkan pada sebuah perangkat lunak dan perangkat keras yang nantinya dapat melakukan sebuah pekerjaan secara khusus guna meminimalkan sumber daya dan sebagai peringatan dini.

\section{TINJAUAN PUSTAKA}

\subsection{Sistem}

Sistem merupakan suatu kumpulan atau himpunan dari unsur, komponen, atau variable yang terorganisir, saling interaksi, saling tergantung satu sama lain dan terpadu [1]. Sistem juga merupakan suatu kesatuan yang terdiri atas komponen atau elemen yang terhubung secara bersama-sama untuk memudahkan aliran informasi, materi atau energi untuk mencapai suatu tujuan [2].

\subsection{Monitoring}

Monitoring merupakan sebuah mekanisme yang sudah menyatu dalam memeriksa yang sudah ada untuk memastikan bahwa semua berjalan untuk direncanakan dan memberi kesempatan agar penyesuaian dapat dilakukan secara metodologis [3]. Monitoring juga dapat didefinisikan sebagai suatu kegiatan untuk mengkaji apakah kegiatan yang dilaksanakan telah sesuai dengan rencana, mengidentifikasi masalah yang timbul agar 
langsung dapat diatasi, melakukan penilaian apakah pola kerja dan manajemen yang digunakan sudah tepat untuk mencapai tujuan, mengetahui kaitan antara kegiatan dengan tujuan untuk memperoleh ukuran kemajuan [1]

\subsection{Server}

Server adalah sebuah sistem komputer yang menyediakan jenis layanan dalam sebuah jaringan komputer. Salah satu layanan yang diberikan oleh server adalah layanan penyimpanan data [4]. Server adalah komputer yang dapat memberikan service ke client [5].

\subsection{Mikrokontroler}

Mikrokontroler (pengendali mikro) pada suatu rangkaian elektronik berfungsi sebagai pengendali yang mengatur jalannya proses kerja dari rangkaian elektronik [6]. Mikrokontroler (microcontroller) adalah sebuah sistem mikroprosesor dimana didalamnya sudah terdapat CPU, Read Only Memory (ROM), Random Access Memory (RAM), Input-Output, timer, interrupt, clock dan peralatan internal lainnya yang sudah saling terhubung dan terorganisasi dengan baik dalam satu chip yang siap dipakai [7].

\subsection{Sensor}

Sensor adalah komponen yang dapat merespon kondisi lingkungan yang diberikan[8]. Sensor adalah elemen sistem yang secara efektif berhubungan dengan proses dimana suatu variabel sedang diukur dan menghasilkan suatu keluaran dalam bentuk tertentu tergantung pada variabel masukannya, dan dapat digunakan oleh bagian sistem pengukuran yang lain untuk mengenali nilai variabel tersebut [9].

\subsection{Website}

Website merupakan sekelompok halaman web (web page), dan pada umumnya bagian dari suatu nama domain (domain name) atau sub domain dalam World Wide Web (www) di internet [10]. Website adalah sejumlah halaman web (situs) yang memiliki topik saling terkait dan terhubung dan terkadang disertai pula dengan berkas gambar, video, atau jenisjenis berkas lainnya [11].

\section{METODOLOGI PENELITIAN}

\subsection{Metodelogi Pengembangan Sistem}

Untuk perancangan penelitian ini, peneliti menggunakan model prototype. Pada model prototipe ada 3 tahapan yaitu sebagai berikut :

\section{Pengumpulan data}

Pada tahapan ini dilakukan pengumpulan data dari bagian administrator ICT dengan cara mendengarkan kebutuhan dari ruangan server ICT.

2. Merancang dan membuat prototipe sesuai kebutuhan sistem

Pada tahap ini dilakukan perancangan dan pembuatan prototipe sistem yang dibuat disesuaikan dengan kebutuhan sistem yang telah didapat dari pengumpulan data sebelumnya.

\section{Pengujian prototipe}

Pada tahap ini hasil prototipe yang dibuat akan diuji coba selanjutnya dilakukan evaluasi terhadap kekurangan yang ada. Jika diperlukan akan diadakan pengembangan untuk memperbaiki prototipe yang ada.

\subsection{Analisis Sistem}

Sebelum melakukan perancangan sebuah sistem maka sebaiknya dilakukan analisis sistem terlebih dahulu pada alat yang akan dibangun. Hal yang dilakukan yaitu membuat skema rancangan alat yang akan dibuat yaitu input sensor kemudian hasil pembacaan sensor pada Arduino uno kemudian ditampilkan dalam bentuk website, LCD dan buzzer. Analisis sistem yang akan digunakan bisa di lihat melalui diagram flowchart di bawah ini: 


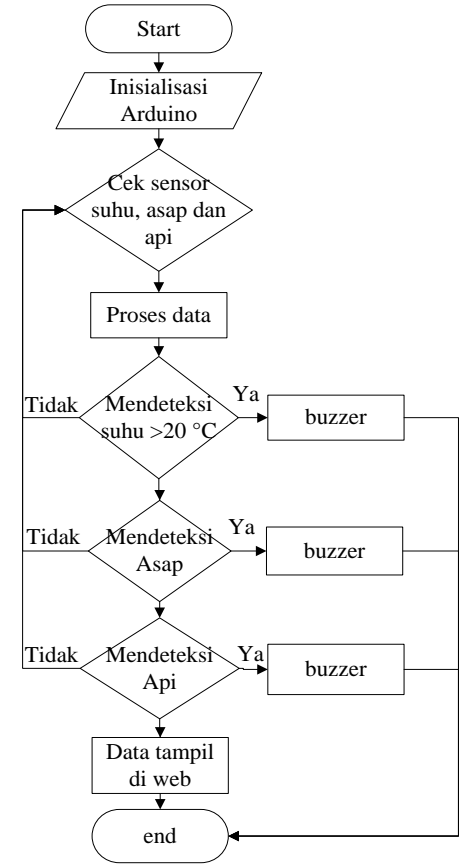

Gambar 1. Flowchart alat monitoring ruangan ICT

\subsection{Perancangan Desain Sistem}

Sistem ini dirancang untuk memantau 3 macam masukan yaitu suhu, asap dan api pada perangkat server yang hasilnya dapat dilihat dari LCD dan website. Alat ukur ini dipasangkan diantara perangkat server untuk mendapatkan informasi berupa suhu, asap dan api yang kemudian dikirim ke database. Apabila suhu melebihi batas yang telah ditentukan oleh pengguna, maka alat akan secara otomatis menghidupkan buzzer. Selanjutnya apabila alat ini mendeteksi adanya asap dan api, maka alat tersebut menghidupkan buzzer.

\subsection{Metode Pengujian Sistem}

Pada pengujian sistem ini yaitu menggunakan metode fungsional. Metode fungsional yang dipakai ini menitik beratkan kepada setiap fungsi dari masing-masing blok sistem, berikut pengujianya antara lain:

1. Pengujian Catu Daya

Pengujian catu daya bertujuan untuk mengetahui tegangan kerja dengan menggunakan multimeter. Catu daya yang digunakan menggunakan tenaga listrik Direct Current (DC) sebesar 5 Volt.

2. Pengujian Input

Pengujian input pada sensor DHT11, MQ-2 dan DFR0011 membutuhkan tegangan supply sebesar 5 volt. Pengujian ini meliputi pengujian tingkat sensitifitas sensor terhadap objek yang diterima.

\section{Pengujian Proses}

Pengujian proses dilakukan terhadap arduino uno. Pengujian ini meliputi tegangan yang dibutuhkan oleh arduino uno agar dapat beroperasi yaitu 5 volt sedangkan tegangan input pada board adalah 6-20 volt. Rentang tegangan input yang dianjurkan adalah 7-12 volt.

\section{Pengujian Output}

Pengujian output dilakukan pada rangkaian LCD dan buzzer. Pengujian dilakukan meliputi fungsi output pada setiap masing-masing rangkaian agar dapat berjalan sesuai dengan apa yang diharapkan.

\section{HASIL DAN PEMBAHASAN}

\subsection{Hasil Perangkat Keras}

1. Hasil Input Sensor DHT11, Sensor MQ-2, Sensor DFR0067 dan Arduino

Pada hasil input sensor DHT11, Sensor MQ-2, Sensor DFR0067 dan arduino terdapat pin $\mathrm{V}$ dihubungkan ke pin 5 volt ke Arduino Uno. Gnd pada sensor DHT11, Sensor MQ-2, Sensor DFR0067 dihubungkan ke pin Ground Arduino Uno. Sedangkan pin data input pada sensor DHT11 dihubungkan ke pin A5 Arduino Uno, pin data input pada sensor MQ-2 dihubungkan ke pin A4 Arduino Uno dan pin data input pada sensor DFR0067 dihubungkan ke pin A3 Arduino Uno. 
Jusikom : Jurnal Sistem Komputer Musirawas Vol 05 No 01 Juni 2020

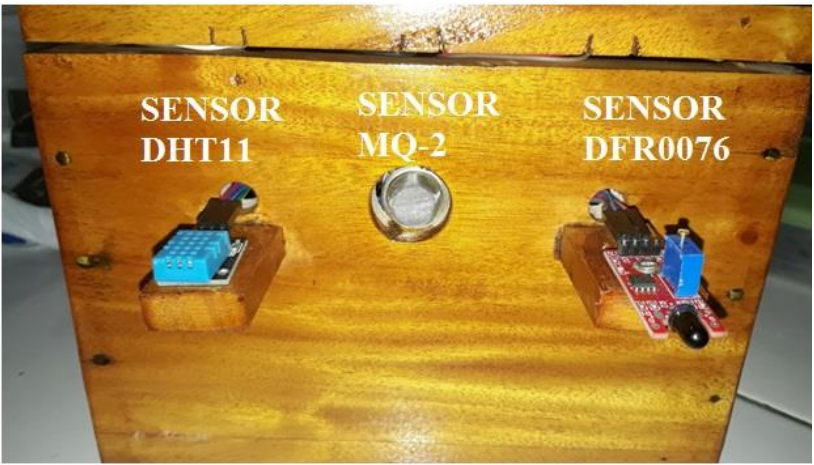

Gambar 2. Hasil input alat monitoring

2. Hasil Output Arduino Uno dengan buzzer dan modul LCD

Hasil output dari sistem monitoring suhu, asap dan api adalah menggunakan buzzer sebagai output suara apabila sistem mendeteksi suhu tingggi, mendeteksi asap dan api. Sedangkan pada LCD menampilkan nilai suhu dan asap yang di deteksi oleh sensor DHT11dan sensor MQ-2.

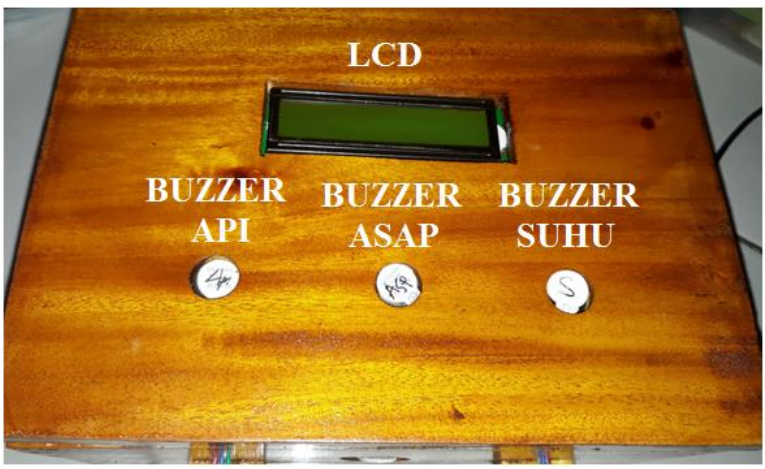

Gambar 3. Hasil output alat monitoring
Taufik Rahman,

Andri Anto Tri Susilo, Wiwit Lestari

3. Hasil Alat Monitoring sensor DHT11, MQ-2, DFR0067, LCD, buzzer dengan arduino uno

Hasil prototype alat monitoring Ruangan Server ICT dapat dilihat pada gambar 4 sebagai berikut:

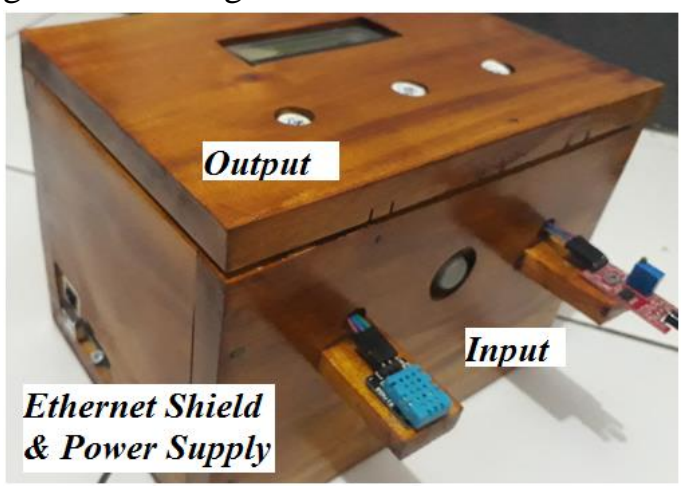

Gambar 4. Prototype alat monitoring suhu, asap dan api

\subsection{Hasil Desain Sistem}

1. Tampilan Halaman Login

Berikut ini adalah tampilan website pada menu login yang dapat dilihat pada Gambar 5 sebagai berikut :

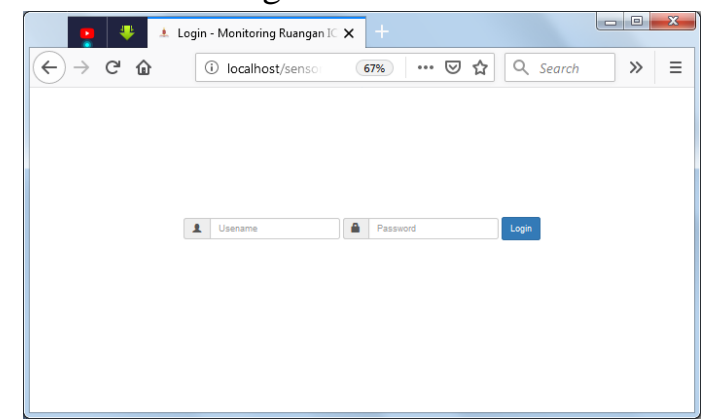

Gambar 5. Tampilan halaman Login

2. Tampilan Halaman Utama

Berikut ini adalah tampilan website pada menu utama yang dapat dilihat pada Gambar 6 sebagai berikut :

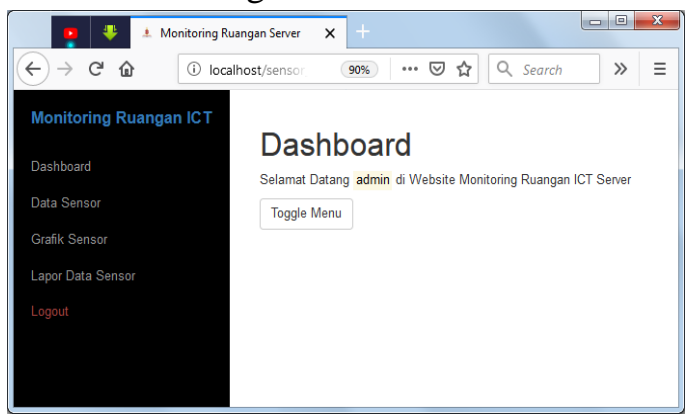

Gambar 6. Tampilan halaman Utama 
3. Tampilan Halaman lihat data sensor

Untuk melihat data input sensor yang sudah tersimpan di database maka admin bisa memilih menu lihat data sensor. Berikut ini adalah tampilan website pada menu lihat data sensor pada Gambar 7 sebagai berikut

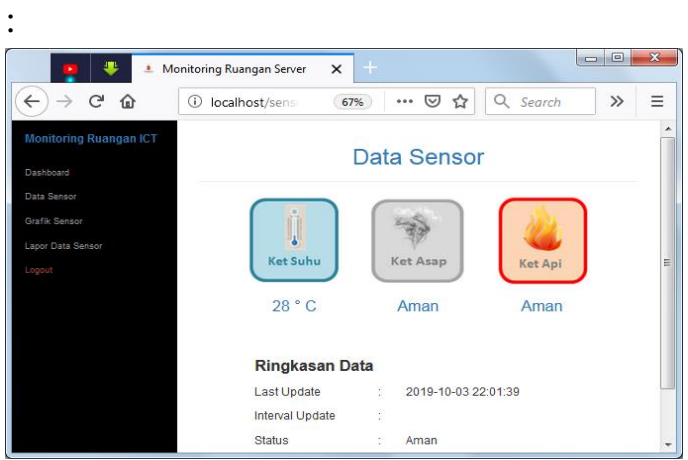

Gambar 7. Tampilan halaman Lihat Data Sensor

4. Tampilan Halaman lihat grafik sensor Untuk melihat data input sensor dalam bentuk grafik yang tersimpan di database maka admin bisa memilih menu lihat data grafik sensor. Berikut ini adalah tampilan website pada menu lihat data grafik sensor pada Gambar 8 sebagai berikut :

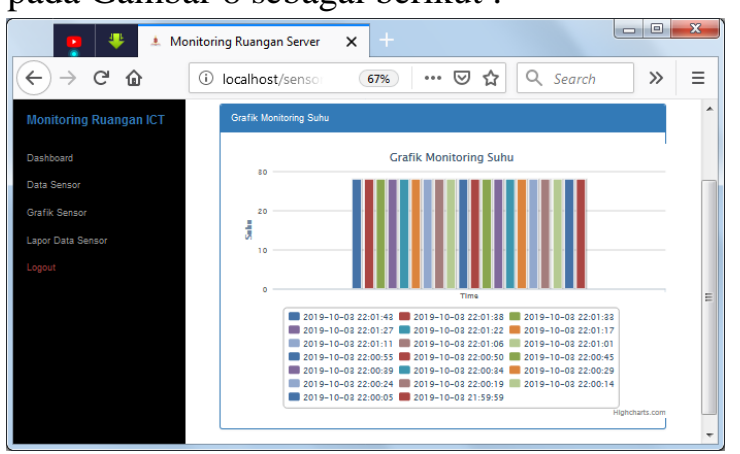

Gambar 8. Tampilan Halaman Grafik

5. Tampilan Halaman Laporan data sensor

Untuk mendapatkan hasil data input sensor yang sudah tersimpan didatabase dalam bentuk file excel maka admin bisa memilih menu laporan data data sensor. Berikut tampilan website pada menu laporan data sensor pada Gambar 9 sebagai berikut :

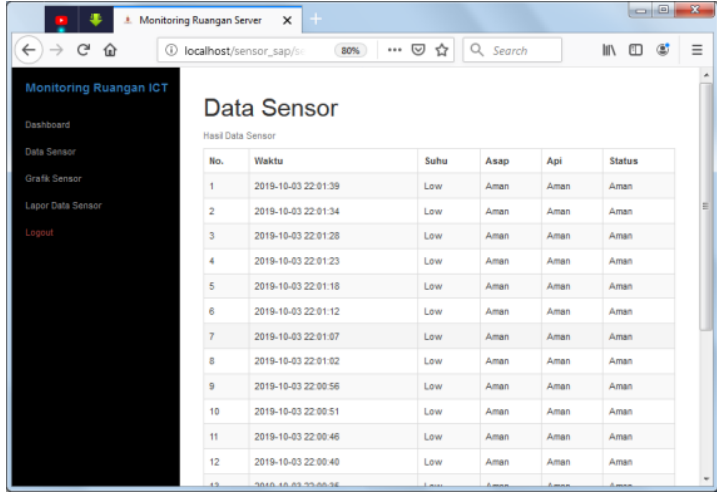

Gambar 9. Tampilan Halaman Laporan Data Sensor

\subsection{Pembahasan Rangkaian Alat}

Sensor suhu DHT11 mendeteksi suhu ruangan ICT server, sensor MQ2 mendeteksi asap dan sensor api mendeteksi api lalu hasil dari ketiga sensor tersebut diproses oleh arduino lalu dikirim ke dalam database dan di tampilkan kedalam halaman website.

\subsection{Pembahasan Web}

Halaman web yang telah dibuat menampilkan seluruh input data sensor suhu, asap dan api kemudian mengirimkan hasil data sensor kedalam database sehingga dalam pembahasan web akan di bahasa tabel database dan tampilan menu web.

Dalam membuat website ini menggunakan 3 tabel database yaitu tabel tb_user untuk menyimpan data admin yang bisa login, tabel sensor_dua untuk menyimpan data sensor suhu dan asap, tabel sensor_api untuk meyimpan data sensor api. Berikut adalah gambar database yang telah dibuat pada gambar 10 yaitu sebagai berikut

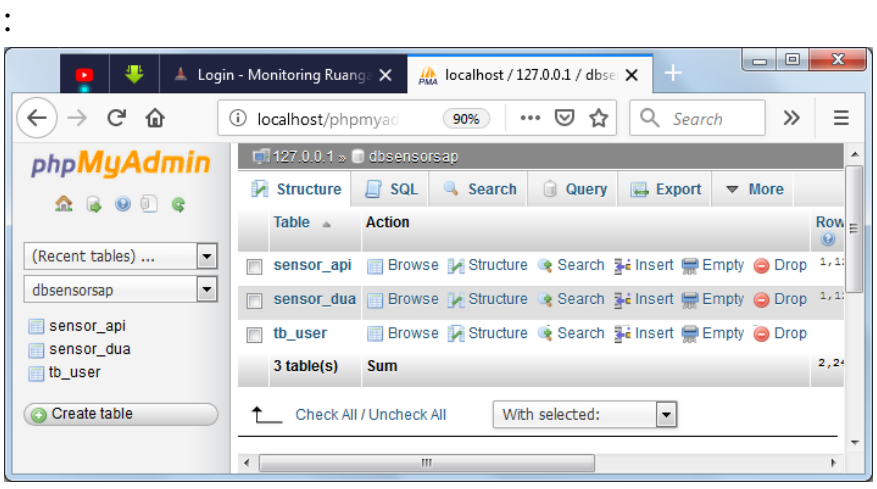

Gambar 10. Tabel database 
Di dalam tampilan website terdapat beberapa menu diantaranya yaitu

1. Menu Home berfungsi sebagi tampilan awal pada website.

2. Menu Data Sensor berfungsi untuk menampilkan nilai data sensor DHT11, sensor MQ-2 dan sensor DFR0067 yang terdeteksi dan tersimpan di database.

3. Menu Data Grafik berfungsi untuk menampilkan grafik dari data suhu ruangan ICT Server.

4. Menu Laporan Data Sensor berfungsi untuk mecari data pada waktu yang di inginkan selain ditampilkan hasil data sensor juga bisa di download.

5. Menu Login berfungi untuk masuk kehalaman web admin.

\section{KESIMPULAN}

Dari pembahasan dan pengujian pada penelitian dapat disimpulkan dari Sistem Monitoring Suhu, Asap dan Api Ruangan Server Information and Communication Technology (ICT) Universitas Bina Insan mengunakan Arduino berbasis Website yaitu sebagai berikut:

1. Sistem Monitoring Suhu, Asap dan Api Ruangan ICT Server memberikan dapat informasi secara berkala mengenai temperatur ruangan, medeteksi asap dan juga api.

2. Alat monitoring ruangan ini dapat membantu menampilkan hasil sensor yang disimpan di database dan dapat ditampilkan di website sehingga dapat membantu bagian administrator dalam memonitoring selama 24 jam secara realtime.

\section{SARAN}

Saran yang dapat diberikan penulis pada penelitian ini agar dapat dikembangkan kedepanya serta disempurnakan dengan adanya penambahan-penambahan menu sehingga dapat mengontrol alat dari website.

\section{DAFTAR PUSTAKA}

A. Herliana and P. M. Rasyid, "SISTEM INFORMASI MONITORING

PENGEMBANGAN SOFTWARE PADA TAHAP DEVELOPMENT BERBASIS WEB," J. Inform., vol. 3, no. 1, 2016, doi: https://doi.org/10.31311/ji.v3i1.281.

[2] Abdullah, "Sistem Deteksi dan Monitoring Kondisi Kadar Kepekatan Asap dengan Sensor Asap dan Camera Tracker," Ilmu Fis. dan Teknol., vol. 2, no. 1, pp. 1-7, 2018.

[3] L. Sunardi, "Web Based Temperature dan Humidity Monitoring Ruangan Laboratorium Komputer SMA Negeri 9 Lubuk Linggau," Sigmata, vol. 5, no. 1, 2017.

[4] C. Umam, L. B. Handoko, and G. M. Rizqi, "Implementation And Analysis High Availability Network File System Based Server Cluster," J. Transform., vol. 16, no. 1, p. 31, 2018 , doi: 10.26623/transformatika.v16i1.841.

[5] H. Nanang, A. Fuadi, and N. Farhanah, "Pengembangan Aplikasi Remote Spesifikasi Dekstop Berbasis Client Server," InforSAINS, vol. 2, no. 3, pp. 1-8, 2008.

[6] H. Andrianto and A. Dermawan, Arduino Belajar Cepat dan Pemprograman, 2nd ed. Bandung: Informatika Bandung, 2017.

[7] Suherman, I. Andriyanto, and S. Dwiyatno, "Rancang Bangun Alat Ukur Temperatur Suhu Perangkat Server Menggunakan Sensor Lm35 Bebasis Sms Gateway," Prosisko, vol. 2, no. 1, pp. 42-63, 2015.

[8] Y. N. Jatmika, Cara Mudah Merakit Robot untuk Pemula, I. Jogjakarta: 
FlashBooks, 2011.

[9] Rafiuddin Syam, Dasar Dasar Teknik Sensor. Makassar: Fakultas Teknik Universitas Hasanuddin, 2013.

[10] MADCOMS, Aplikasi Web Database Dengan Dreamweaver dan PHP-MySQL. Yogyakarta: C.V ANDI OFFSET, 2011.

[11] R. Rachmanto, 9 Langkah Praktis Membuat Website Gratis, I. Jakarta: PT Elex Media Komputindo, 2017. 